\title{
Translation of metabolite profiling to infectious diseases
}

\author{
Muireann Coen*, Elaine Holmes \\ From Immunodiagnosis of Tuberculosis: New Questions, New Tools \\ Virginia, VA, USA. 21-23 September 2008
}

The field of metabonomics involves generation of complex metabolic profiles of tissues and biofluids using analytical platforms such as nuclear magnetic resonance (NMR) spectroscopy and mass spectrometry (MS). Metabolic profiles can reflect changes following an intervention, such as administration of a drug or onset of a disease. Multivariate modeling tools are applied to discriminate profiles and identify biomarkers that differentiate between phenotypes of interest such as control and diseased states. One advantage of metabonomics is that it is a 'top-down' approach that reflects an integrated systems response as it takes into account genetic and environmental status. A variety of analytical technologies can be utilized; however NMR spectroscopy and MS represent the most powerful and widely used tools as they can capture information on thousands of metabolites in a biofluid in a single analytical run. The challenge of extracting relevant metabolic information from the complex spectral data sets is tackled using pattern recognition tools that reduce the dimensionality of the data, such as principal components analysis (PCA) and partial least squares regression (PLS) and many novel statistically-driven approaches have been developed in recent years.

An example of the application of metabonomics to differentiate cerebrospinal fluid (CSF) samples from clinical bacterial and viral meningitis cases was presented. The application of NMR-based metabolic profiling greatly improved the speed and specificity of sample classification. In addition, patterns of CSF metabolites that altered following bacterial and viral meningitis infection were identifed. Furthermore, gram-stain negative samples of meningococcal meningitis were clearly differentiated from all other cases of bacterial meningitis. A larger

\footnotetext{
* Correspondence: m.coen@imperial.ac.uk

Biomolecular Medicine, Department of Surgery and Cancer, Faculty of

Medicine, Imperial College London, London SW7 2AZ, UK
}

study is intended to validate these findings and to also incorporate metabolic profiling of non-invasively collected urine rather than CSF.

In terms of diagnostics, metabonomics has many diverse application potentials and could be useful in studying the metabolic signature reflecting host response, in identifying pathogen-derived metabolites, and in differentiating single infection versus co-infection. It may prove a powerful tool for providing systems level insight into mechanisms of pathology associated with infectious diseases, such as Mycobacterium tuberculosis. With respect to therapeutic monitoring, both in vitro and in vivo metabonomic-led approaches could offer insight into the response of both the pathogen and host to intervention, drug resistance, therapeutic efficacy and toxicology.

Published: 17 December 2010 doi:10.1186/1753-6561-4-S3-O10
Cite this article as: Coen and Holmes: Translation of metabolite profiling
to infectious diseases. BMC Proceedings 2010 4(Suppl 3):O10.

Submit your next manuscript to BioMed Central and take full advantage of:

- Convenient online submission

- Thorough peer review

- No space constraints or color figure charges

- Immediate publication on acceptance

- Inclusion in PubMed, CAS, Scopus and Google Scholar

- Research which is freely available for redistribution 